\title{
Fetal membranes and placentation in Chiroptera
}

\author{
A. Gopalakrishna and K. B. Karim \\ Department of Zoology, Institute of Science, Nagpur, India
}

\section{Introduction}

The development of the fetal membranes and the definitive structure of the placenta have been studied in one or a few representatives of the following families of Chiroptera: Pteropidae (Gohre, 1892a, b; Selenka, 1892; Kohlbrugge, 1913; Keibel, 1922; van der Sprenkel, 1932; Moghe, 1951, 1956; Wimsatt, 1958; Karim, 1971, 1972a), Rhinopomatidae (Srivastava, 1952; Gopalakrishna, 1958), Emballonuridae (Gopalakrishna, 1958; Wimsatt \& Gopalakrishna, 1958), Noctilionidae (Anderson \& Wimsatt, 1953, 1963), Megadermatidae (Gopalakrishna, 1950b, 1958; Gopalakrishna \& Khaparde, 1978a, b), Rhinolophidae (Hamlett, 1934; Gopalakrishna \& Bhiwgade, 1974; Bhiwgade, 1976, 1977), Hipposideridae (Gopalakrishna, 1958; Gopalakrishna \& Moghe, 1960; Jeevaji, 1973), Phyllostomatidae (Hamlett, 1935; Wislocki \& Fawcett, 1941; Fleming, 1971; Rasweiler, 1972, 1974; Bodley, 1974; Bleier, 1975), Desmodontidae (Wimsatt, 1954; Bjorkman \& Wimsatt, 1968; Quintero \& Rasweiler, 1974), Vespertilionidae (several early authors and, more recently, Wimsatt, 1944, 1945, 1958; Gopalakrishna, 1949, 1950a, 1958; Enders \& Wimsatt, 1968; Potts \& Racey, 1971; Phansalkar, 1972; Sapkal, 1973) and Molossidae (Hamlett, 1934; Mossman, 1937; Stephens, 1962, 1969; Stephens \& Easterbrook, 1968, 1969, 1971; Stephens \& Cabral, 1971). These studies have revealed that there are considerable differences among the members of the different families, and sometimes among members of the same family, in the details of the development of the fetal membranes and the final structure of the placenta.

Observations on the development of fetal membranes and placentation made by a group of workers in this laboratory during the past few years, and much of which is yet unpublished, are incorporated in the present review. The fetal membranes and the structure of the placenta of Rousettus leschenaulti, Taphozous melanopogon, Hipposideros speoris, H. lankadiva, Pipistrellus ceylonicus chrysothrix, $P$. dormeri, P. m. mimus, and Tadarida aegyptiaca are described for the first time, and additional information or corrections of earlier erroneous observations on Cynopterus sphinx gangeticus, Pteropus giganteus, Megaderma lyra lyra, Hipposideros fulvus, and Miniopterus schreibersii fluiginosus are also included here.

\section{Amnion}

Four modes of amniogenesis are noticed among bats.

(1) The early amniotic cavity arises by the breakdown and degeneration of some of the cells in the centre of the embryonic mass, and, as the embryonic plate expands, the roof of the amniotic cavity becomes stretched to form a thin layer which persists as the ectodermal component of the amnion over which extends extra-embryonic mesoderm. Such a method of amnion formation occurs in Rousettus leschenaulti, Pteropus giganteus and Scotophilus heathi, and was reported earlier in Glossophaga soricina (Hamlett, 1935), Scotophilus wroughtoni (Gopalakrishna, 1949) and Desmodus rotundus murinus (Wimsatt, 1954).

(2) In Megaderma l. lyra, Hipposideros speoris, H. lankadiva and all the pipistrellids studied here, the primitive amniotic cavity is formed as in the species described above, but, with the expansion of the embryonic plate and the primitive amniotic cavity, the original roof of the 
primitive amniotic cavity ruptures and is lost. Hence, for a short time the amniotic cavity is roofed over by the basal layer of trophoblast. However, folds, which soon develop from the sides of the embryonic plate, grow dorsally and arch over the amniotic cavity and form the ectodermal component of the definitive amnion. Extra-embryonic mesoderm envelops this layer to establish the definitive amnion. Such a method of amnion formation had been reported earlier in Vespertilio murinus (Duval, 1894, 1895, 1896), Vesperugo noctula (van der Stricht, 1899), Miniopterus schreibersii (Celestino da Costa, 1920), Vesperugo leisleri (Ramaswami, 1933), and Myotis lucifugus lucifugus (Wimsatt, 1944).

(3) The amnion develops in an unusual manner in Cynopterus sphinx gangeticus (Moghe, 1956) and possibly in $C$. marginatus (Keibel, 1922). In these species, after the primitive amniotic cavity is formed by the degeneration of some of the cells of the embryonic mass, the embryonic mass is pushed deeper into the blastocyst cavity by a proliferation of precociously formed extraembryonic mesoderm. Thus, a mass of spongy tissue intervenes between the hollow embryonic mass and the trophoblast layer. Folds developing from the sides of the embryonic mass grow dorsally and arch over, enclosing a cavity in the spongy tissue. For a short time, therefore, there are two cavities lying over one another - the original primitive amniotic cavity and the secondary amniotic cavity - separated by the roof of the primitive amniotic cavity. With the expansion of the embryonic plate the partition between the two cavities ruptures and they become confluent. The roof of the secondary amniotic cavity forms the ectodermal component of the definitive amnion after it is encompassed by the extra-embryonic mesoderm (Text-fig. 1).

(4) The amnion in Tadarida brasiliensis cynocephala (Stephens, 1962) forms exclusively by the development of folds. It is interesting to note here that not only is this the sole bat in which this method of amniogenesis has been reported, but it is also the only species in which the blastocyst establishes its first contact with the uterine wall by its abembryonic pole. In Molossus
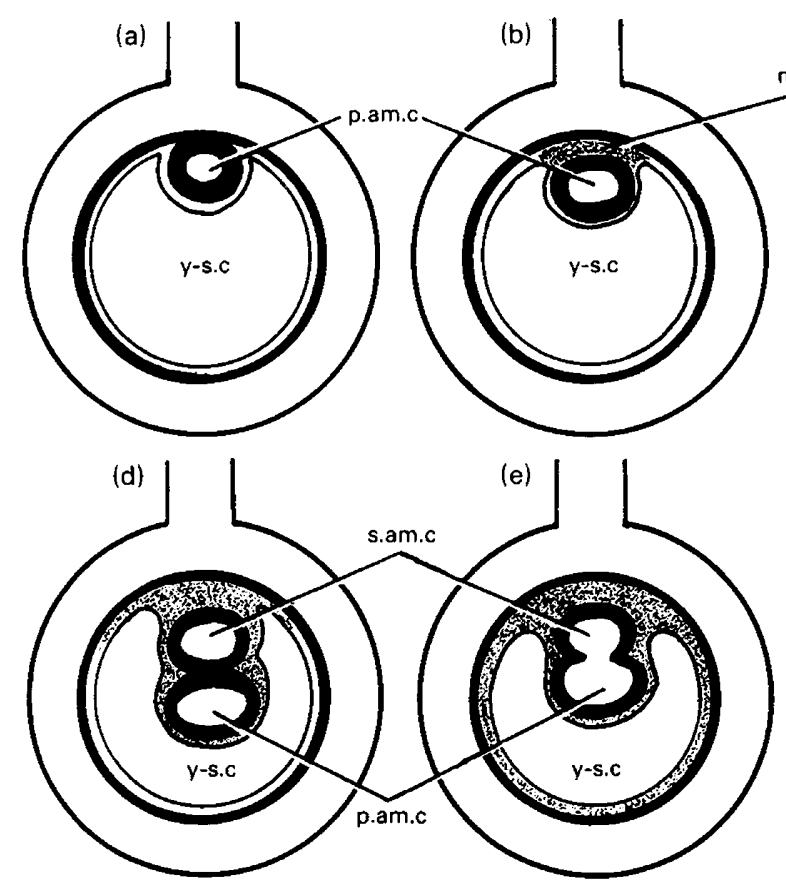

Text-fig. 1. Schematic representation of the development (a-f) of the amnion in Cynopterus sphinx gangeticus. am, amnion; mes, mesoderm; p.am.c, primitive amniotic cavity; s.am.c, secondary amniotic cavity; y-s.c, yolk-sac cavity. 
rufus and $M$. obscurus (Sansom, 1932), in which early implanted blastocysts have been described, the blastocyst comes into contact with the uterine wall on its entire surface, and the embryonic mass has a central primitive amniotic cavity.

From the above, it appears that the mode of formation of the amnion, whether by cavitation or by folding, is determined by the topographical relationship between the uterus and the implanted blastocyst. Where the blastocyst is attached either at its embryonic pole as in Pteropus giganteus (Moghe, 1951) and vespertilionids (Wimsatt, 1944; Gopalakrishna, 1949) or circumferentially as in Rousettus leschenaulti, Megaderma l. lyra, Hipposideros speoris, Miniopterus schreibersii fuliginosus, the primitive amniotic cavity develops by cavitation as there is no space for the development of the folds. On the other hand, in Tadarida brasiliensis cynocephala, in which the embryonic mass hangs freely into the uterine lumen, amniogenesis takes place by fold formation since space is available for the development of the folds.

\section{Yolk sac}

The developmental history of the yolk sac in bats follows three distinct courses with minor variations.

(1) The simplest course of development is illustrated by Noctilio labialis minor (Anderson \& Wimsatt, 1963), Megaderma l. lyra, Desmodus rotundus (Wimsatt, 1954), Artibeus jamaicensis parvipes (Wislocki \& Fawcett, 1941) and all vespertilionids (Wimsatt, 1945; Gopalakrishna, $1950 \mathrm{a}$ ) in which the abembryonic segment of the yolk sac remains permanently bilaminar or trilaminar either in contact with the uterine wall, as in Noctilio labialis minor, Megaderma l. lyra, Artibeus jamaicensis parvipes, Desmodus rotundus murinus and Miniopterus schreibersii fuliginosus, or remains hanging freely in the uterine lumen as in all other vespertilionids. The vascular splanchnopleure becomes progressively 'invaginated' (Wimsatt, 1945) towards the abembryonic segment of the yolk-sac wall.

As the vitelline vessels extend from the embryonic to the abembryonic pole, the endodermal cells, which were squamous to begin with, become cuboidal (P1. 1, Fig. 1), and the separation of the splanchnopleure is accompanied by a further hypertrophy of the endodermal cells. In the case of Megaderma l. lyra and all the vespertilionids, as the yolk sac splanchnopleure pushes towards the abembryonic yolk-sac wall, it becomes folded and the mesodermal cells also undergo enormous hypertrophy. During the final stages of gestation the splanchnopleure undergoes almost complete collapse resulting in the near obliteration of the yolk-sac lumen which persists only in some places as narrow streak-like spaces (Pl. 1, Fig. 2). Whereas the endoderm in these bats remains as a single layer of cuboidal cells lining the remnants of the yolk-sac lumen, the mesodermal elements occur as numerous folds of large vacuolated cells projecting into the exocoelom (Pl. 1, Fig. 3). The enormous hypertrophy of the cellular elements of the collapsed splanchnopleure gives it a gland-like appearance. The yolk sac of Tadarida brasiliensis cynocephala (Stephens, 1962) and T. aegyptiaca appears to undergo the highest specialization among bats belonging to this category, since in these species the close approximation of the collapsed walls of the yolk sac and the hypertrophy of the endodermal cells nearly obliterates the yolk-sac lumen (Pl. 1, Figs. 4 and 5).

(2) The second mode of vitellogenesis is illustrated by Rhinopoma kinneari (Srivastava, 1952; Gopalakrishna, 1958), Taphozous longimanus (Gopalakrishna, 1958), T. melanopogon, Rhinolophus rouxi (Bhiwgade, 1977), Hipposideros bicolor pallidus (Gopalakrishna, 1958), $H$. f. fulvus (Gopalakrishna \& Karim, 1975), H. speoris (Jeevaji, 1973) and H. lankadiva. In these bats the yolk sac is vascularized on its entire surface, and the vascular splanchnopleure becomes completely separated from the chorion and undergoes progressive collapse. With the advancement of pregnancy the collapsed yolk-sac splanchnopleure is pulled towards the placental disc and finally comes to lie adjacent to the chorio-allantoic placental disc-a position exactly 
opposite to the one it occupied during the earlier stages of development. The earlier histological changes in the yolk sac of these bats are similar to those described for Megaderma l. lyra and vespertilionids. However, after the complete separation of the splanchnopleure with its progressive collapse, the endodermal lining composed of hypertrophied cells is thrown into numerous folds, and the mesodermal cells, which also undergo hypertrophy, form a cover to the endodermal layer on its exocoelomic surface. During the final stages of gestation the yolk sac occurs as a collapsed bag and persistent narrow streak-like remnants of the lumen give this structure a gland-like appearance (Pl. 1, Fig. 6).

(3) The manner of development of the yolk sac and its ultimate structure in the megachiropteran species (Robin, 1881; Gohre, 1892a, b; van der Sprenkel, 1932; Moghe, 1951, 1956; Wimsatt, 1958; Gopalakrishna \& Karim, 1972a, b; Karim, 1972a) are unique. In these animals the early development of the yolk sac is similar to what has been described for Rhinopoma, Taphozous, Rhinolophus and hipposiderids. However, during the last quarter of pregnancy the shrivelled yolk sac loses its lumen completely and occurs as a solid vascular lobulated gland-like structure (Pl. 1, Fig. 7) closely abutting against the placental disc. Histologically, each lobe of the yolk sac consists of numerous acinus-like groups of hypertrophied endodermal cells, mostly lacking central lumina, embedded in a mass of mesenchyme (Pl. 1, Fig. 8). Each 'acinus' is enveloped by a sheath of mesodermal cells and fine fibres. The surface of the entire gland is covered by a distinct layer of cuboidal mesodermal cells, each with a large, spherical, darkly staining nucleus.

The most detailed studies on the histochemistry and fine structure of the yolk sac of bats are those carried out by Wimsatt $(1948,1949)$ and Enders, Wimsatt \& King (1976) on the yolk sac of Myotis l. lucifugus and Stephens (1962) and Stephens \& Easterbrook $(1968,1969,1971)$ on the yolk sac of Tadarida brasiliensis cynocephala. These studies indicate that the yolk sac is in some way concerned with absorption of material from the uterine wall during earlier stages of gestation, and in the storage of glycogen and lipids during advanced stages of pregnancy. Absorption of proteinous material by the mesothelial cells from the exocoelomic fluid was demonstrated by Enders et al. (1976) in Myotis l. lucifugus.

\section{PLATE 1}

Fig. 1. Part of the vascularized yolk-sac wall to show cuboidal endodermal cells (arrow) of Pipistrellus ceylonicus chrysothrix. $\times 460$.

Fig. 2. Part of the collapsed yolk-sac splanchnopleure of Pipistrellus dormeri. Note mesodermal folds (arrow). $\times 56$.

Fig. 3. Part of the yolk sac of Pipistrellus dormeri to show the single layer of cuboidal endodermal cells (arrow) lining the narrow yolk-sac lumen. Note the hypertrophied mesodermal cells (arrowhead). $\times 410$.

Fig. 4. Part of the yolk-sac splanchnopleure of Tadarida aegyptiaca. $\times 56$.

Fig. 5. Part of Fig. 4. Note the formation of nests of hypertrophied endodermal cells (thick arrow) surrounded by enlarged mesothelial cells (arrowhead). Remnants of the yolk-sac cavity (thin arrow) persist in some places. $\times 560$.

Fig. 6. Part of the collapsed yolk-sac splanchnopleure of Taphozous melanopogon. Arrow points to the remnant of the yolk-sac lumen. $\times 88$.

Fig. 7. Part of the lobulated yolk-sac gland of Pteropus giganteus giganteus. Note the acinuslike groups of endodermal cells (arrow) lying in the mesenchyme. $\times 56$.

Fig. 8. Part of Fig. 7. Note the acinus-like groups of endodermal cells. A layer of mesothelium (arrowhead) lines the lobe. $\times 560$.

Fig. 9. Section of the gravid uterus of Pteropus giganteus giganteus to show the cup-shaped trophoblastic placenta (arrow). $\times 22$. 
PLATE 1
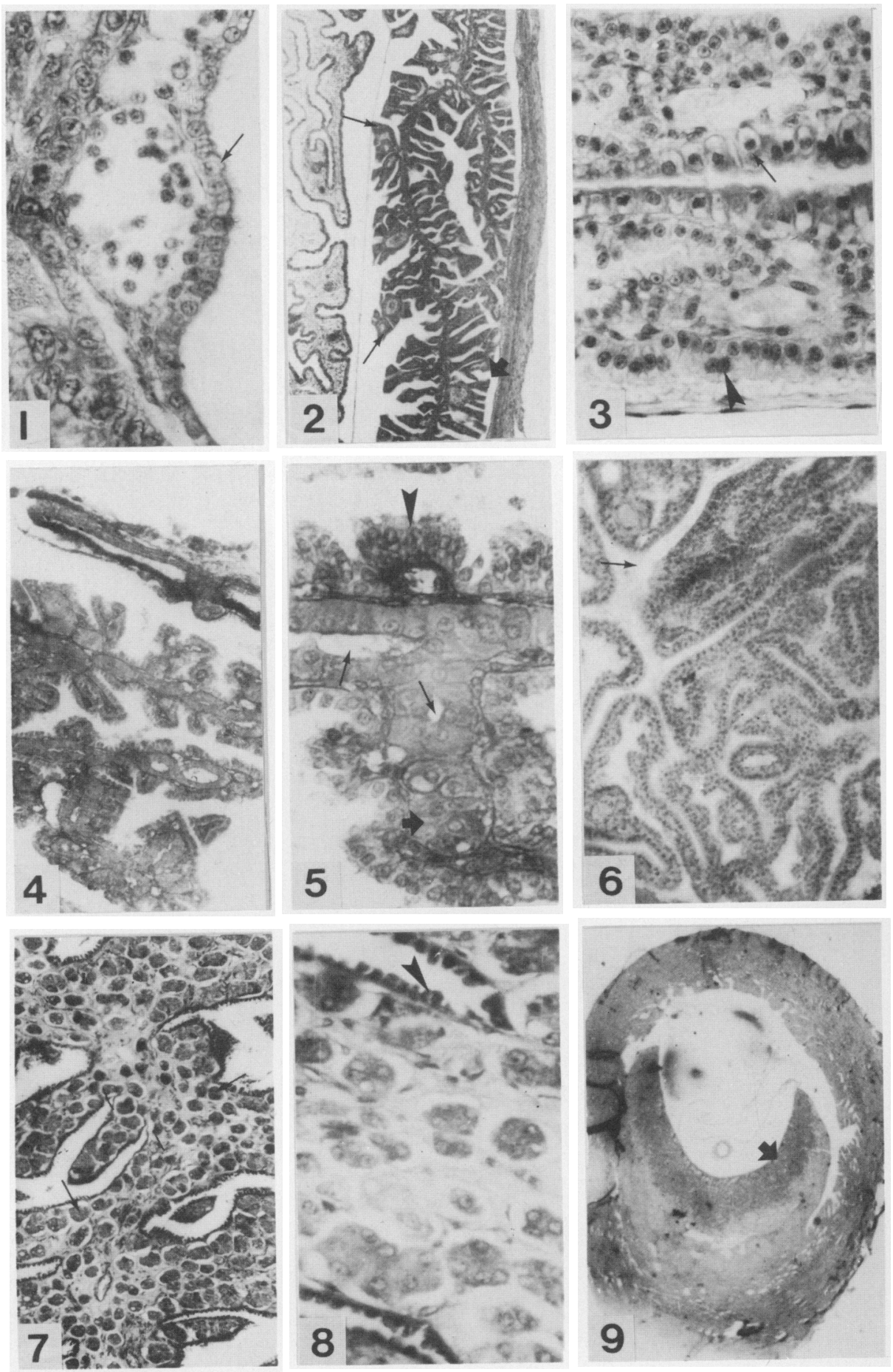
PLATE 2
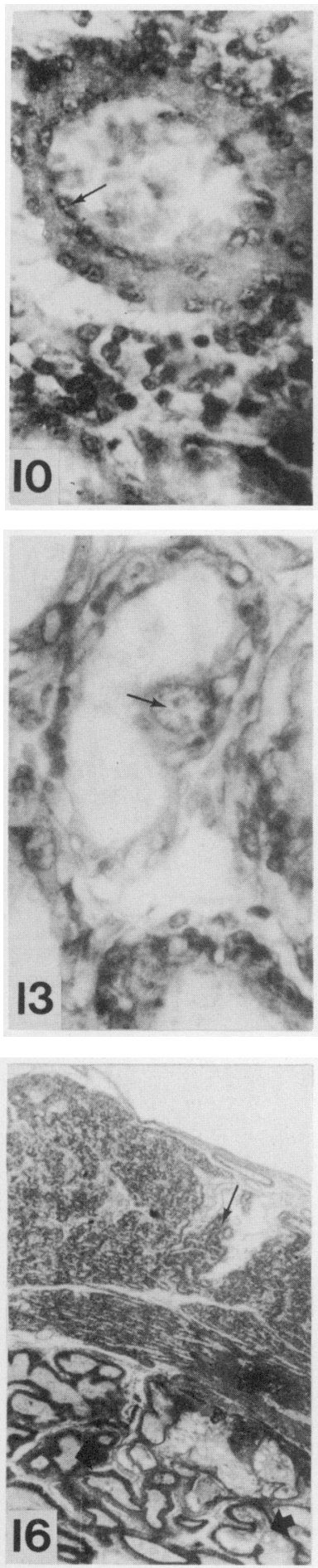
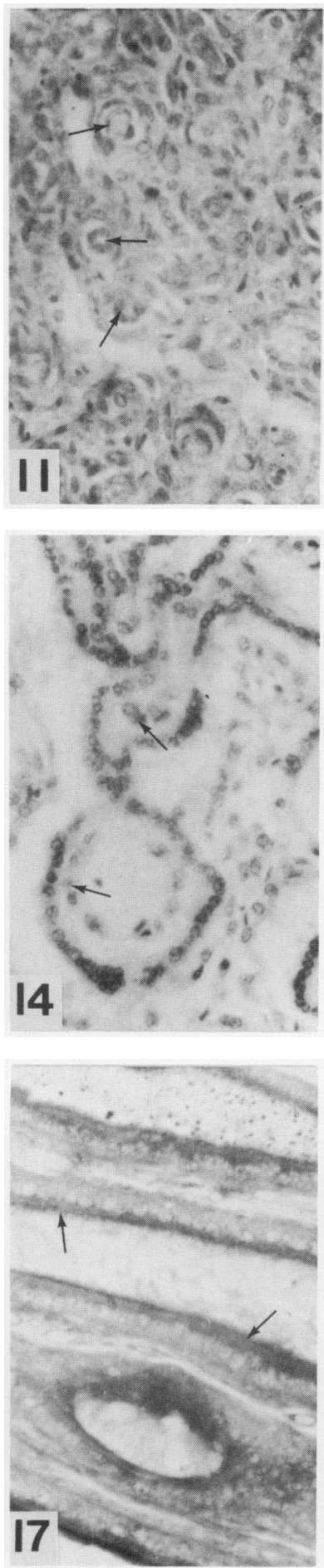
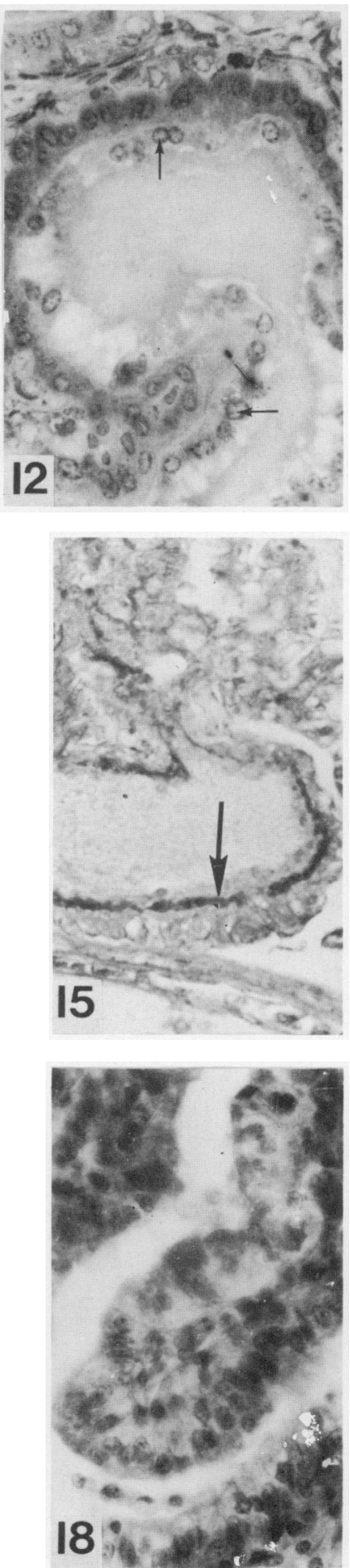


\section{Allantois}

In most bats whose embryology has been studied, the allantois carries a vesicle, which reaches its maximum extent when the fetus is at the limb-bud stage of development and when the placenta is in the form of a cup. With the progressive consolidation of the placenta into a discoid structure the allantoic vesicle becomes reduced until it is either completely obliterated as in most bats, or it persists as a small space within the mesenchyme beneath the placental disc as in hipposiderid bats (Gopalakrishna, 1958; Gopalakrishna \& Moghe, 1960). A narrow allantoic duct or a solid endodermal cord persists either throughout the length of the umbilical cord as in all Megachiroptera, Megaderma l. lyra, Rhinolophus rouxi, all hipposiderids, phyllostomids (Hamlett, 1935; Wislocki \& Fawcett, 1941) and Miniopterus schreibersii, or only for a short distance in the proximal segment of the umbilical cord as in Taphozous longimanus, $T$. melanopogon and Scotophilus heathi. There is no remnant of the allantoic duct in the umbilical cord of pipistrellids and Tadarida aegyptiaca. The allantois has been described as small, nonvesicular and transient in Desmodus rotundus murinus (Wimsatt, 1954).

\section{Definitive disposition of the fetal membranes}

The chorio-allantoic placenta is discoid in all bats, but its position with respect to the morphology of the uterus varies among the different families. It is mesometrial in all Megachiroptera (Text-fig. 2a) (Mossman, 1937; Moghe, 1951, 1956), Rhinopoma kinneari (Text-fig. 2b) (Srivastava, 1952; Gopalakrishna, 1958), Megaderma lyra lyra (Text-fig. 2c), Rhinolophus rouxi (Gopalakrishna \& Bhiwgade, 1974; Bhiwgade, 1977), hipposiderids (Gopalakrishna, 1958; Gopalakrishna \& Moghe, 1960; Karim, 1972b), Tadarida brasiliensis cynocephala (Stephens, 1962) and $T$. aegyptiaca. In Taphozous melanopogon (Text-fig. 2d) and all other emballonurid bats so far studied (Gopalakrishna, 1958; Wimsatt \& Gopalakrishna, 1958) the final placenta consists of two parts, a mesometrial part, which is in the form of a sac-like haematoma, and a lateral part which is discoid. The placental disc is located between the antimesometrial and lateral sides in Noctilio labialis minor (Anderson \& Wimsatt, 1963). In Rhinolophus rouxi (Gopalakrishna \& Bhiwgade, 1974; Bhiwgade, 1977) and all hipposiderids (Text-fig. 2e), the presence of a deep cleft

\section{PLATE 2}

Fig. 10. Part of the ripe placenta of Cynopterus sphinx gangeticus. Arrow points to the persistent maternal endothelium within the placental tubule. $\times 410$.

Fig. 11. Part of the definitive placenta of Taphozous melanopogon. Note the endothelial cells (arrow) in the placental tubules. $\times 220$.

Fig. 12. Placental tubule of Megaderma lyra lyra at advanced pregnancy. Note the hypertrophied endothelial cells (arrow). $\times 560$.

Fig. 13. Part of the late placenta of Megaderma lyra lyra to show a cytotrophoblastic giant cell (arrow). $\times 410$.

Fig. 14. Part of the ripe placenta of Rhinolophus rouxi. Note the row of enlarged endothelial cells (arrow) within the placental tubule, and a distinct row of darkly staining nuclei of the syncytiptrophoblast surrounding the endothelium. $\times 410$.

Fig. 15. Part of a placental tubule of Rousettus leschenaulti to show the discontinuous interstitial membrane (arrow). PAS, $\times 560$.

Fig. 16. Section showing a part of the main (thin arrow) and a part of the accessory placental disc (thick arrow) of Miniopterus schreibersii fuliginosus. $\times 56$.

Fig. 17. Part of the accessory placenta of Miniopterus schreibersii fuliginosus (PAS reaction). Note the thick PAS-positive membrane (arrow) lining the maternal sinusoids. $\times 410$.

Fig. 18. Part of a chorionic villus in the haematoma of Taphozous melanopogon to show ingested maternal erythrocytes within the trophoblastic cells. $\times 560$. 

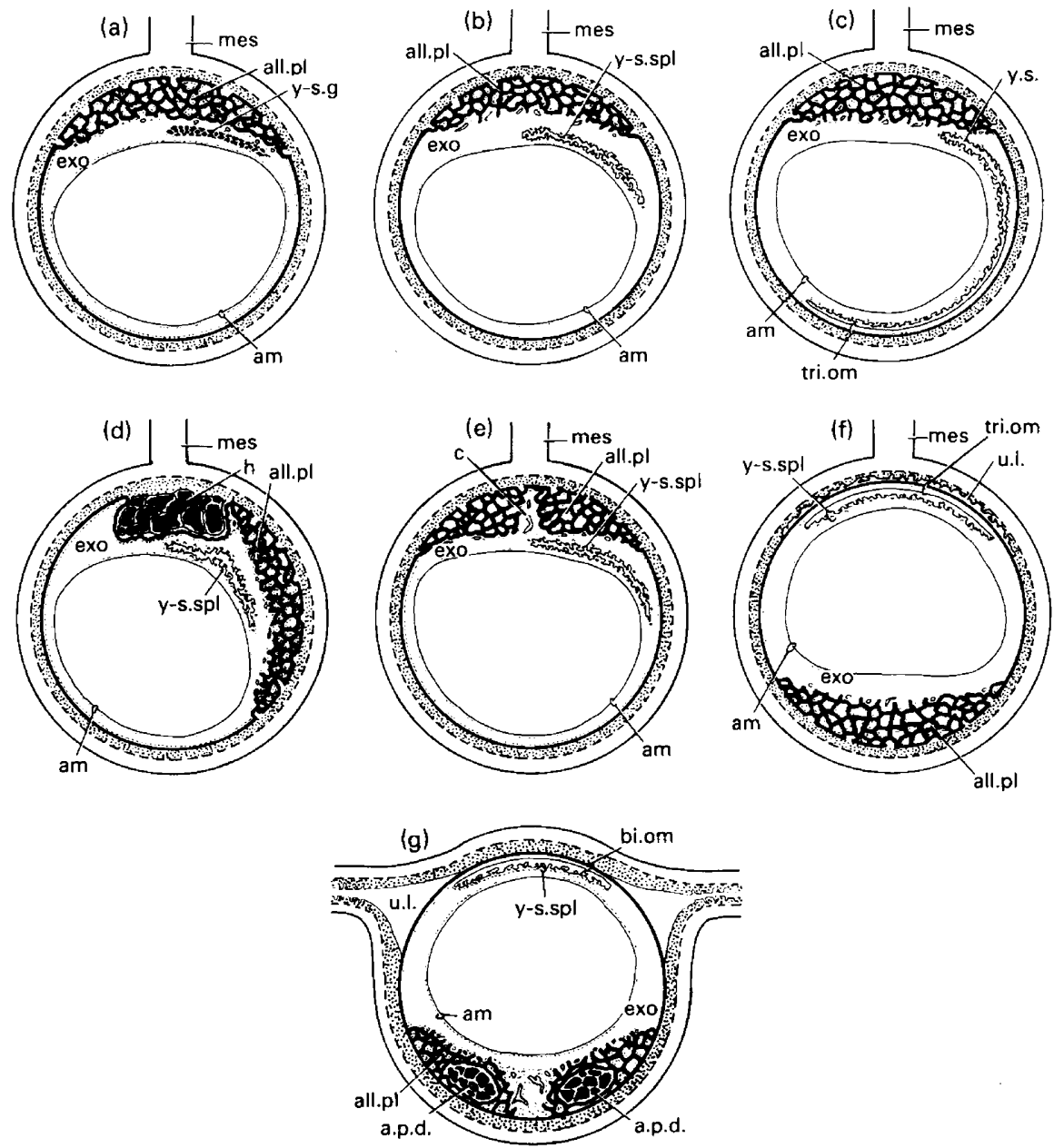

Text-fig. 2. Schematic representations of the arrangement of the fetal membranes in (a) pteropid bats; (b) Rhinopoma kinneari; (c) Megaderma lyra lyra; (d) Taphozous melanopogon; (e) hipposiderid bats; (f) Pipistrellus mimus mimus; and (g) Miniopterus schreibersii fuliginosus. all.p., allantoic placenta; am, amnion; a.p.d., accessory placental disc; bi.om, bilaminar omphalopleure; c, cleft in centre of placenta; exo, exocoelom; h, haematoma; mes, mesometrium; tri.om, trilaminar omphalopleure; u.l., uterine lumen; y.s., yolk sac; y-s.g, yolk-sac gland; y-s.spl, yolk-sac splanchnopleure.

in the centre of the placenta divides the disc into two. The disc is antimesometrial in Phyllostomatidae (fundic) (Hamlett, 1934, 1935; Wislocki \& Fawcett, 1941; Rasweiler, 1972, 1974), Desmodus rotundus murinus (Wimsatt, 1954) and Vespertilionidae. Within the vespertilionids, there is a saucer-shaped placental disc located on the antimesometrial side in Vesperugo leisleri (Ramaswami, 1933), Myotis l. lucifugus (Wimsatt, 1945), Scotophilus temmincki (= Scotophilus wroughtoni) (Gopalakrishna, 1950), Scotophilus heathi (Ramakrishna \& Madhavan, 1977) and all pipistrellids (Text-fig. 2f), but the placenta of Miniopterus schreibersii fuliginosus (Text-fig. $2 \mathrm{~g}$ ) and other subspecies of $M$. schreibersii (Branca, 1927; Kempermann, 1929; Malassine, 1970) consists of two distinct discs which lie one behind the other in the cranio-caudal axis of the uterus with a wide gap between them. Further, embedded in the thickest part of each disc near its maternal border, there is a smaller, circular, discoid accessory placenta whose histology is very different from that of the surrounding placental disc. 
The collapsed yolk sac lies abutting against the placental disc on its fetal surface in all Megachiroptera, Rhinopoma kinneari, all emballonurids, Rhinolophus rouxi and all hipposiderids. In Megaderma l. lyra and Tadarida brasiliensis cynocephala (Stephens, 1962) and T. aegyptiaca, a small area of the abembryonic part of the yolk sac retains its contact with the chorion, but a major part of the separated splanchnopleure lies beneath, and by the side of, the placental disc. In all the phyllostomatids, Desmodus rotundus murinus and vespertilionids the yolk sac retains a wide area of contact with the chorion and lies on the mesometrial side, diametrically opposite the position of the placental disc.

\section{Placentation}

From a morphological point of view three distinct types of placenta are formed in a chronological sequence during the development of most bats although there may be a certain degree of overlapping, and more than one kind of placenta may exist concurrently but at different regions of the uterus at a given stage of gestation.

\section{Trophoblastic placenta}

This type is formed soon after the implantation of the blastocyst as a result of the invasion of the syncytiotrophoblast into the endometrium. The extent of development of the trophoblastic placenta depends on the nature of the attachment of the blastocyst. Whereas the trophoblastic placenta is formed on all sides of the implantation chamber and thus forms a spherical shell in Rousettus, Cynopterus, Taphozous, Megaderma, Hipposideros and Tadarida, it is limited to the embryonic hemisphere of the implantation chamber in Pteropus (Pl. 1, Fig. 9), Noctilio labialis minor (Anderson \& Wimsatt, 1963) and all vespertilionids. In Desmodus rotundus murinus (Wimsatt, 1954), all phyllostomids (Hamlett, 1935; Rasweiler, 1974) in which implantation is interstitial, and Miniopterus schreibersii in which implantation is superficial, the entire blastocyst wall comes into contact with the uterine endometrium, but the trophoblast in the abembryonic wall of the blastocyst does not actually invade the endometrium to any great extent, even though the uterine epithelium is lost from this region also. Histologically, the trophoblastic placenta consists of a mass of syncytiotrophoblast which surrounds maternal blood capillaries in the endometrium after having destroyed the endometrial connective tissue. With the extension of the mesoderm the trophoblastic placenta is converted into the chorionic placenta. This structure is present on the dorsal side of the embryonic plate, since the yolk-sac wall pre-empts the rest of the gestation chamber.

\section{Yolk-sac placenta}

The apposition of the yolk-sac wall against the uterine wall establishes the yolk-sac placenta which is at first non-vascular. The extension of the vitelline vessels into the yolk-sac wall converts the non-vascular yolk-sac placenta into the chorio-vitelline placenta. In all the bats the extension of the exocoelom into the yolk-sac wall separates the vascular splanchnopleure from the chorion, thereby abolishing the chorio-vitelline placenta progressively from the embryonic to the abembryonic region. A chorio-vitelline placenta is not formed in Desmodus rotundus murinus and phyllostomids (Wimsatt, 1954) because the extra-embryonic mesoderm does not extend beyond the margin of the placental disc.

\section{Chorio-allantoic placenta}

In all bats, with the exception of Tadarida brasiliensis cynocephala (Stephens, 1962) and $T$. aegyptiaca, the allantois grows towards, and carries fetal blood vessels to, the already existing 
chorionic placenta which is invariably on the dorsal side of the embryonic plate. This is a matter of some significance because the final placental disc in all bats except Tadarida is located on the side diametrically opposite that where the yolk-sac placenta was earlier present. In Tadarida a thick 'preplacental' pad is formed on the mesometrial side where the blastocyst establishes its first contact with the abembryonic side. But as the splanchnopleure of the yolk sac becomes separated from the chorion in this region, the allantois grows across the exocoelom towards the mesometrial side and comes into contact with the thick placental pad.

During early stages of gestation the allantois spreads over a wide area on the fetal surface in all the Megachiroptera, Rhinopoma, Taphozous, Megaderma, Rhinolophus, hipposiderids and Tadarida. But as the placenta becomes consolidated into a discoid structure, the allantoic vesicle shrinks or disappears.

\section{Histogenesis of the placenta}

The histological changes in the placenta leading to its definitive structure have been described in considerable detail for Desmodus rotundus murinus (Wimsatt, 1954; Bjorkman \& Wimsatt, 1968), Myotis lucifugus lucifugus (Wimsatt, 1945; Enders \& Wimsatt, 1968), Scotophilus temmincki (Gopalakrishna, 1950a) and Tadarida brasiliensis cynocephala (Stephens, 1962, 1969 ) in which the placenta is haemochorial, and for Hipposideros bicolor pallidus (Gopalakrishna \& Moghe, 1960) and Megaderma lyra lyra (Gopalakrishna \& Khaparde, 1978b) in which the placenta is endotheliochorial. The general course of histogenesis in both types of placenta is the same, except for the loss or persistence of the endothelial lining of the maternal vascular channels. Four distinct chronological stages in the histological differentiation of the placenta can be recognized, although there is a considerable degree of overlapping of these stages.

The first stage commences with the implantation of the blastocyst and ends with the formation of the trophoblastic placenta. During this period the cells of the primitive trophoblastic layer undergo proliferation and invade the endometrium after the loss of the uterine epithelium, and form a syncytiotrophoblastic shell either only on the embryonic pole of the blastocyst as in vespertilionids (Wimsatt, 1945; Gopalakrishna, 1949) and Desmodus rotundus murinus (Wimsatt, 1954), or on all sides of the implantation chamber as in the bats which have a circumferential implantation. Even in the latter case, the trophoblast in the embryonic hemisphere is more actively invasive than that in the rest of the regions, except in Tadarida brasiliensis cynocephala (Stephens, 1962) and T. aegyptiaca in which the trophoblast in the abembryonic pole is more actively invasive. In all cases the invading trophoblast is syncytial and surrounds maternal blood capillaries after causing histolytic erosion of the decidual tissue. Within a short time after implantation the thick trophoblastic layer occupies a considerable portion of the presumptive decidua basalis.

During the second stage the basal cytotrophoblastic layer grows into the syncytiotrophoblastic shell in the form of solid columns. The third stage, which commences soon after the cytotrophoblastic cords have extended deep into the syncytiotrophoblast, is characterized by a hollowing out of the cytotrophoblastic cords at the fetal surface of the placenta, and the entry of fetal mesenchymal tissue into the hollows of the cytotrophoblastic cords. As a result of the progressive widening of the cavities within the cytotrophoblastic cords, the maternal vascular channels surrounded by syncytiotrophoblast come to resemble tubules hanging from the uterine wall. In stained sections these placental tubules, consisting of an inner maternal vascular channel surrounded by a layer of syncytiotrophoblast and a layer of cytotrophoblast, are prominent and stand out against the lightly stained fetal mesenchyme. Very soon, fetal blood capillaries enter the mesenchymal cores of the cytotrophoblastic columns and effect the fetal vascularization of the placenta. Subsequently, the placental tubules undergo branching and anastomosis to establish the definitive placental labyrinth. 
Further histological changes which establish the definitive structure of the placenta concern the fate of the endothelium of the maternal blood capillaries. These changes vary among the different species and determine the nature of the final placenta of which two broad types can be recognized: endotheliochorial or vasochorial, and haemochorial. Accessory placental structures are also developed in some bats.

\section{Endotheliochorial or vasochorial placenta}

A typical endotheliochorial placenta in which the maternal endothelial cells persist until term occurs in Pteropus g. giganteus, Cynopterus sphinx gangeticus (Pl. 2, Fig. 10), Rhinopoma kinneari (Srivastava, 1952; Gopalakrishna, 1958), Taphozous longimanus (Gopalakrishna, 1958), T. melanopogon (P1. 2, Fig. 11), Noctilio labialis minor (Anderson \& Wimsatt, 1963), Megaderma l. lyra (Pl. 2, Fig. 12) (Wimsatt, 1958; Gopalakrishna, 1958, Gopalakrishna \& Khaparde, 1978b), Rhinolophus rouxi (Gopalakrishna \& Bhiwgade, 1974; Bhiwgade, 1977) and all hipposiderid bats (Gopalakrishna, 1958; Gopalakrishna \& Moghe, 1960; Karim, 1972b). In all these species the endothelium occurs as a distinct lining of hypertrophied, closely arranged cells during the first three-quarters of pregnancy. During this period the two trophoblastic layers - an inner sheath of syncytiotrophoblast and an outer sheath of cytotrophoblast - which envelop the maternal endothelium are distinct. However, during the final quarter of pregnancy the endothelial lining becomes rapidly attenuated and the cells of this layer become progressively smaller and less numerous. A few days before parturition the endothelial lining is reduced to a thin cytoplasmic lamina in which there are a few darkly staining, fusiform, widely scattered nuclei. Concomitantly, there is also a change in the trophoblastic sheath around the maternal capillaries. In Pteropus, Cynopterus, Rhinopoma, Taphozous, Rhinolophus rouxi (Pl. 2, Fig. 14) and hipposiderids, the distinction between the cytotrophoblastic and syncytiotrophoblastic layers cannot be distinguished at the light microscopic level. Hence, the ripe placenta in these species appears to consist of a mass of syncytium surrounding the maternal blood capillaries with attenuated endothelium. The fetal mesenchyme and capillaries are compressed into thin strands between the placental tubules. In Megaderma lyra lyra the cells of the cytotrophoblast become converted into giant cells (Pl. 2, Fig. 13) before they get incorporated in the general syncytium.

\section{Haemochorial placenta}

This type of placenta occurs in Rousettus leschenaulti, Desmodus rotundus murinus (Wimsatt, 1954; Bjorkman \& Wimsatt, 1968), Glossophaga soricina (Hamlett, 1935), Artibeus jamaicensis parvipes (Wislocki \& Fawcett, 1941), Myotis l. lucifugus (Wimsatt, 1945; Enders \& Wimsatt, 1968), Vesperugo leisleri (Ramaswami, 1933), Scotophilus temmincki (Gopalakrishna, 1950), Pipistrellus sp. (Phansalkar, 1972; Gopalakrishna \& Sapkal, 1974; Gopalakrishna \& Karim, 1972a), Tadarida brasiliensis cynocephala (Stephens, 1962, 1969) and $T$. aegyptiaca. In all these species the maternal endothelium is lost from the capillaries in the main placenta relatively early in development. The ripe placenta of Desmodus rotundus murinus (Bjorkman \& Wimsatt, 1968), Myotis l. lucifugus (Enders \& Wimsatt, 1968), Scotophilus heathi (Ramakrishna \& Madhavan, 1977), Pipistrellus ceylonicus chrysothrix (Phansalkar, 1972) and P. m. mimus (Gopalakrishna \& Karim, 1972a) is haemodichorial since both cyto- and syncytiotrophoblast are present, whereas the placenta of Tadarida brasiliensis cynocephala (Stephens, 1962, 1969), T. aegyptiaca and Pipistrellus dormeri (Gopalakrishna \& Sapkal, 1974) is haemomonochorial. Although the cytotrophoblast is the persistent layer in the placenta of Tadarida, the syncytiotrophoblast remains in the definitive placenta of Pipistrellus dormeri.

A significant and constant component of the placental tubules of all the bats is a PASpositive, Azan-positive interstitial membrane which occurs between the endothelial lining and the syncytiotrophoblast in the vasochorial placenta, and lies embedded in a cytoplasmic lamina 
bordering the maternal sinusoids in the haemochorial placenta. The interstitial membrane is discontinuous (PI. 2, Fig. 15) and network-like and the cytoplasm of the syncytiotrophoblast is in continuity with the cytoplasmic lamina bordering the lumen of the placental tubules (Karim, Wimsatt \& Gopalakrishna, 1978). Wimsatt (1958), who first recognized the presence of the interstitial membrane in the placental tubules of bats, adduced that the material of this membrane may be wholly or partly derived from the syncytiotrophoblast. The thickness of the interstitial membrane appears to be approximately proportional to the calibre of the maternal vascular channels which undergo dilatation as pregnancy advances and as the endothelial lining becomes progressively attenuated. These facts also indicate the possibility that the interstitial membrane may not be entirely the remnant of the basement membrane of the endothelium of the maternal blood capillaries in the placenta. Further, since the only other structure which is topographically adjacent to the interstitial membrane is the syncytiotrophoblast, it is highly suggestive that the syncytiotrophoblast is in some way responsible for the increase in the thickness of the interstitial membrane. However, these facts do not preclude the possibility that the basement membrane of the original endothelial lining may also become incorporated in the definitive interstitial membrane of the mature placenta of all bats.

The interstitial membrane of Myotis l. lucifugus and Desmodus rotundus murinus has no direct contact with the lumen of the blood space, but lies beneath an ectoplasmic layer of cytoplasm which is continuous with the syncytiotrophoblast (Enders \& Wimsatt, 1968; Bjorkman \& Wimsatt, 1968). These authors also observed that the interstitial membrane may have a dual origin, part of it being the remnant of the basement membrane of the maternal endothelium and part of it being contributed by the trophoblast. Enders \& Wimsatt (1968) noted that cytoplasmic processes from the syncytiotrophoblast in Myotis l. lucifugus push through the basement membrane and spread out underneath the maternal endothelium, thereby loosening its attachment to the basement membrane. The endothelial cells become separated, and are lost. Hence, "the interstitial membrane", which was present earlier as the basement membrane of the endothelium, gets a covering of cytoplasm from the syncytiotrophoblast and is "converted into an intrasyncytial lamina, perforated only at irregular intervals by syncytial tongues which spread out over its upper surface forming a nearly continuous layer". In Tadarida brasiliensis cynocephala, Stephens (1969) noticed the presence of a discontinuous envelope of "homogeneous substance" over which the trophoblastic cytoplasm remains as a layer in direct contact with the maternal blood. The topographical situation of this 'homogeneous substance' leaves little doubt that it is the same as the "interstitial membrane" described by Wimsatt (1958), Bjorkman \& Wimsatt (1968) and Enders \& Wimsatt (1968).

\section{Accessory placental structures}

Several kinds of accessory placental structures involving the chorio-allantoic membrane have been described in bats; the following are a few examples. The occurrence of a villous syndesmochorial placenta on the maternal border of the main placenta has been reported in Myotis $l$. lucifugus (Wimsatt, 1945) and Megaderma l. lyra (Gopalakrishna \& Khaparde, 1978b). The parietal layer of membranous chorion is in intimate contact with the endometrium throughout gestation in hipposiderid and molossid bats. Technically, this should also be considered as an accessory placenta since physiological exchange can be expected to occur here between fetal and maternal tissues.

The placenta of Miniopterus schreibersii fuliginosus has within each main placental disc a smaller disc in which there is a labyrinth of large sinusoids filled with maternal blood (Text-fig. $2 \mathrm{~g}$; Pl. 2, Fig. 16). The wall of the labyrinth is composed of a thick, porous, PAS-positive membrane enveloped by a distinct row of large, highly basophilic trophoblastic cells (Pl. 2, Fig. 17). The interrelationship between the main placenta and these accessory discs remains to be studied. 
In the emballonurid bats (Gopalakrishna, 1958; Wimsatt \& Gopalakrishna, 1958), the mesometrial part of the placenta becomes converted into a sac-like haematoma during the second half of gestation, and numerous folds of the chorion hang into the haematoma. Maternal erythrocytes are actively ingested by the cells of the chorion (Pl. 2, Fig. 18) which is directly bathed in extravasated maternal blood in the haematoma.

We are grateful to Professor W. A. Wimsatt, Professor of Zoology, Cornell University, Ithaca, New York, for reading the manuscript and for giving helpful suggestions for its improvement.

\section{References}

Anderson, J.W. \& Wimsatt, W.A. (1953) The foetal membranes and placentation of the tropical American noctilionid bat, Dirias albiventer minor. Anat. Rec. 117, 573-574.

Anderson, J.W. \& Wimsatt, W.A. (1963) Placentation and foetal membranes of the Central American noctilionid bat, Noctilio labialis minor. Am. J. Anat. 112, 181-202.

Bhiwgade, D.A. (1976) Observations on some early stages of development and implantation of the blastocyst of Rhinolopus rouxi (Temminck). Proc. Indian Acad. Sci. B 84, 201-209.

Bhiwgade, D.A. (1977) Development of the foetal membranes in the Indian horse-shoe bat, Rhinolophus rouxi (Temminck), Proc. Indian Acad. Sci. B 86, 61-72.

Bjorkman, N.H. \& Wimsatt, W.A. (1968) The allantoic placenta of the vampire bat (Desmodus rotundus murinus): a reinterpretation of its structure based on electron microscopic observations. Anat. Rec. 162, 83-97.

Bleier, W.J. (1975) Early embryology and implantation in the California leaf-nosed bat, Macrotus californicus. Anat. Rec. 182, 237-254.

Bodley, H.D. (1974) Ultrastructural development of the chorio-allantoic placental barrier in the bat, Macrotus waterhousii. Anat. Rec. 180, 351-368.

Branca, A. (1927) Recherches sur la placentation des Cheiroptères. Archs Zool. exp. gén. 66, 291-450.

Celestino da Costa, A. (1920) Sur la formation de l'amnios chez les Cheiroptères (Miniopterus schreibersii) et en general chez les Mammifères. Mems Soc. port. Sci. nat. Sér. Biológica No. 3, 1-5.

Duval, M. (1894) Etudes sur l'embryologie des Cheiroptères. J. Anat. Physiol., Paris 31, 93-160 and 427474.

Duval, M. (1895) Etudes sur l'embryologie des Cheiroptères. J. Anat. Physiol., Paris 32, 105-164 and 420454.

Duval, M. (1896) Etudes sur l'embryologie des Cheiroptères. J. Anat. Physiol., Paris 33, 1-31.

Enders, A.C. \& Wimsatt, W.A. (1968) Formation and structure of the hemodichorial chorio-allantoic placenta of the bat, Myotis lucifugus lucifugus. Am. J. Anat. 122, 453-489.

Enders, A.C., Wimsatt, W.A. \& King, B.F. (1976) Cytological development of the yolk sac endoderm and protein absorptive mesothelium in the little brown bat, Myotis lucifugus. Am. J. Anat. 146, 1-29.
Fleming, T.H. (1971) Artibeus jamaicensis: Delayed embryonic development in a Neotropical bat. Science, N.Y. 171, 402-403.

Gohre, R. (1892a) Keimbildung des Kalong (Pteropus edulis). In Selenka's Studien uber Entwicklungsgeschichte der Tiere, Vol. 5, 209-217. Wiesbaden.

Gohre, R. (1892b) Dottersack und Placenta von Pteropus edulis, L. In Selenka's Studien uber Entwicklungsgeschichte der Tiere, Vol. 5, 218-233. Wiesbaden.

Gopalakrishna, A. (1949) Studies on the embryology of Microchiroptera, Part IV: An analysis of implantation and early development in Scotophilus wroughtoni (Thomas). Proc. Ind. Acad. Sci. 30, 226242.

Gopalakrishna, A. (1950a) Studies on the embryology of Microchiroptera, Part V: Placentation in the vespertilionid bat, Scotophilus wroughtoni (Thomas). Proc. Indian Acad. Sci. 31, 235-251.

Gopalakrishna, A. (1950b) Studies on the embryology of Microchiroptera, Part VI: Structure of the placenta in the Indian vampire bat, Lyroderma lyra lyra (Geoffroy). (Megadermatidae). Proc. natn. Inst. Sci. India 16, 93-98.

Gopalakrishna, A. (1958) Foetal membranes in some Indian Microchiroptera. J. Morph. 102, 157-197.

Gopalakrishna, A. \& Bhiwgade, D.A. (1974) Foetal membranes in the Indian horse-shoe bat, Rhinolophus rouxi (Temminck). Curr. Sci. 43, 516517.

Gopalakrishna, A. \& Karim, K.B. (1972a) Arrangement of the foetal membranes and the occurrence of a haemodichorial placenta in the vespertilionid bat, Pipistrellus mimus mimus. Curr. Sci. 41, 144-146.

Gopalakrishna, A. \& Karim, K.B. (1972b) The yolk-sac gland in the Indian fruit bat, Rousettus leschenaulti (Desmarest). Curr. Sci. 41, 639-641.

Gopalakrishna, A. \& Karim, K.B. (1975) Development of the foetal membranes in the Indian leaf-nosed bat, Hipposideros fulvus fulvus (Gray). Part II. Placentation. Revue Roum. Biol. Ser. Zool. 20, 257-267.

Gopalakrishna, A. \& Khaparde, M.S. (1978a) Early development, implantation and amniogenesis in the Indian vampire bat, Megaderma lyra lyra (Geoffroy). Proc. Indian Acad. Sci. 87B, 91-104.

Gopalakrishna, A. \& Khaparde, M.S. (1978b) Development of the foetal membranes and placentation in the Indian false vampire bat, Megaderma lyra lyra (Geoffroy). Proc. Indian Acad. Sci. 87B, 179-194. 
Gopalakrishna, A. \& Moghe, M.A. (1960) Development of the foetal membranes in the Indian leaf-nosed bat, Hipposideros bicolor pallidus. Z. Anat. EntwGesch. 122, 137-149.

Gopalakrishna, A. \& Sapkal, V.M. (1974) Foetal membranes in the Indian pipistrellid, Pipistrellus dormeri (Dobson). J. zool. Soc., India 26, 1-9.

Hamlett, G.W.D. (1934) Implantation und Embryonalhullen beiz wei Sudamericanischen Fledermausen. Anat. Anz. 79, 146-149.

Hamlett, G.W.D. (1935) Notes on the embryology of a phyllostomid bat. Am. J. Anat. 56, 327-353.

Jeevaji, I.H. (1973) Early development, development of the foetal membranes and placentation in the Indian leaf-nosed bat, Hipposideros speoris (Schneider). Ph.D. Thesis. Nagpur University, India.

Karim, K.B. (1971) Early development, development of the foetal membranes and placentation in the Indian fruit bat, Rousettus leschenaulti (Desmarest). Ph.D. thesis, Nagpur University, India.

Karim, K.B. (1972a) Development of the yolk sac in the Indian fruit bat, Rousettus leschenaulti (Desmarest). J. Zool. Soc., India 24, 135-147.

Karim, K.B. (1972b) Foetal membranes and placentation in the Indian leaf-nosed bat, Hipposideros fulvus fulvus (Gray). Proc. Indian Acad. Sci. B 76, 71-78.

Karim, K.B., Wimsatt, W.A. \& Gopalakrishna, A. (1978) Structure of the definitive placenta in the Indian bat, Rousettus leschenaulti (Pteropidae). Anat. Rec. 190, 438.

Keibel, F. (1922) Zur Entwicklungsgeschichte einer Grossfledermaus (Cynopterus marginatus). Arch. mikrosk. Anat. EntwMech. 96, 528-554.

Kempermann, C.T. (1929) Die Placenta der Fledermaus Miniopterus und ihre functionelle bedeutung. $Z$. Anat. EntwGesch. 91, 292-303.

Kohlbrugge, J.F.H. (1913) Befruchtung und Keimbildung bei der Fledermaus, Xantharpya amplexicaudata. Verh. K. Acad. Wet., Amsterdam. 17, 1-37.

Malassine, A. (1970) Etude histologique et ultrastructurale du disque placentaire de Minioptere, Miniopterus schreibersii (Chiroptere): Sa nature endothelio-choriale, son caractere endocrine. Archs Anat. microsc. Morph. 59, 99-112.

Moghe, M.A. (1951) Development and placentation in the Indian fruit bat, Pteropus giganteus giganteus (Brunnich). Proc. Zool. Soc., Lond. 121, 703-721.

Moghe, M.A. (1956) On the development and placentation of the megachiropteran bat, Cynopterus sphinx gangeticus. Proc. natn. Inst. Sci. India 22, 48-55.

Mossman, H.W. (1937) Comparative morphogenesis of the foetal membranes and accessory uterine structures. Contr. Embryol. Carnegie Instn 26, 127-246.

Phansalkar, R.B. (1972) Early development and placentation in the vespertilionid bat, Pipistrellus ceylonicus chrysothrix. Ph.D. thesis, Nagpur University, India.

Potts, D.M. \& Racey, P.A. (1971) A light and electron microscope study of early development in the bat, Pipistrellus pipistrellus. Micron 2, 322-348.

Quintero, F. \& Rasweiler, J.J., IV (1974) Ovulation and early embryonic development in the captive vampire bat, Desmodus rotundus. J. Reprod. Fert. 41, 265273.
Ramakrishna, P.A. \& Madhavan, A. (1977) Foetal membranes and placentation in the vespertilionid bat, Scotophilus heathi (Horsefield). Proc. Indian Acad. Sci. $B$ 86, 117-126.

Ramaswami, L.S. (1933) Some stages of the placentation in Vesperugo leisleri (Kuhl). Half-yrly J. Mysore Univ. 7, 1-41.

Rasweiler, J.J., IV (1972) Reproduction in the long tongued bat, Glossophaga soricina. I. Preimplantation development and histology of the oviduct. J. Reprod. Fert. 31, 249-262.

Rasweiler, J.J., IV (1974) Reproduction in the long tongued bat, Glossophaga soricina. II. Implantation, early embryonic development. Am. J. Anat. 139, 136.

Robin, H.A. (1881) Recherches anatomiques sur les mammiferes de l'ordre des Cheiropteres. Annls Sci. nat. 12, 1-181.

Sansom, G.S. (1932) Notes on some early blastocysts of the South American bat, Molossus. Proc. zool. Soc., Lond. Part II, 113-118.

Sapkal, V.M. (1973) Early development, development of the foetal membranes and placentation in the vespertilionid bat, Pipistrellus dormeri (Dobson). Ph.D. thesis, Nagpur University, India.

Selenka, E. (1892) Keimbildung des Kalong (Pteropus edulis). In Selenka's Studien uber Entwicklungsgeschichte der Tiere, Vol. 5, p. 209. Wiesbaden.

Srivastava, S.C. (1952) Placentation in the mouse-tailed bat, Rhinopoma kinneari. Proc. zool. Soc., Bengal 5, 105-131.

Stephens, R.J. (1962) Histology and histochemistry of the placenta and foetal membranes in the bat, Tadarida brasiliensis cynocephala. Am. J. Anat. 111, 259-286.

Stephens, R.J. (1969) The development and the fine structure of the allantoic placental barrier in the bat, Tadarida brasiliensis cynocephala. J. Ultrastruct. Res. 28, 371-398.

Stephens, R.J. \& Easterbrook, N. (1968) Development of the cytoplasmic membranous organelle in the endodermal cells of the yolk sac of the bat, Tadarida brasiliensis cynocephala. J. Ultrastruct. Res. 24, 239-248.

Stephens, R.J. \& Easterbrook, N. (1969) A new cytoplasmic organelle related to both lipid and glycogen storage materials in the yolk sac of the bat, Tadarida brasiliensis cynocephala. Am. J. Anat. 124, 47-58.

Stephens, R.J. \& Easterbrook, N. (1971) Ultrastructural differentiation of the endodermal cells of the yolk sac of the bat, Tadarida brasiliensis cynocephala. Anat. Rec. 169, 207-242.

Stephens, R.J. \& Cabral, L. (1971) Direct contribution of the cytotrophoblast to the syncytiotrophoblast in the diffuse labyrinthine endotheliochorial placenta of the bat. Anat. Rec. 169, 243-252.

van der Sprenkel, H.B. (1932) Persistenz de Dottergefasse in den Embryonen der Fledermaus und ihre Ursache. Z. mikrosk.-anat. Forsch. 28, 185268.

van der Stricht, O. (1899) La fixation de l'oeuf de chauvesouris a l'intereur de l'uterus (Vesperugo noctula). Anat. Anz. Verh. anat. Ges., Jena 13th Meeting. 
Wimsatt, W.A. (1944) An analysis of implantation in the bat, Myotis lucifugus lucifugus. Am. J. Anat. 74, $355-411$.

Wimsatt, W.A. (1945) The placentation in the vespertilionid bat, Myotis lucifugus lucifugus. Am. J. Anat. 77, 1-51.

Wimsatt, W.A. (1948) The nature and distribution of lipoids in the placenta of the bat (Myotis lucifugus lucifugus) with observations on the mitochondria and Golgi apparatus. Am. J. Anat. 82, 393-468.

Wimsatt, W.A. (1949) Cytochemical observations on the fetal membranes and placenta of the bat, Myotis lucifugus lucifugus. Am. J. Anat. 84, 63-142.
Wimsatt, W.A. (1954) The fetal membranes and placentation of the tropical American vampire bat, Desmodus rotundus murinus. Acta anat. 21, 285-341.

Wimsatt, W.A. (1958) The allantoic placental barrier in Chiroptera: a new concept of its organization and histochemistry. Acta anat. 32, 141-186.

Wimsatt, W.A. \& Gopalakrishna, A. (1958) Occurrence of placental hematoma in the primitive sheath-tailed bats (Emballonuridae), with observations on its structure, development and histochemistry. Am. J. Anat. 103, 35-68.

Wislocki, G.B. \& Fawcett, D.W. (1941) The placentation of the Jamaican bat, Artibeus jamaicensis parvipes. Anat. Rec. 81, 307-317. 